\title{
Entrevista com José Augusto Pádua
}

\section{Interview with José Augusto Pádua}

Todos recolhem sua importância, dentro e fora do Brasil, enquanto referência nas pesquisas em História Ambiental. Como você descreveria a sua trajetória enquanto historiador ambiental?

O mais importante, ao meu ver, é realizar o trabalho por si mesmo, com paixão e rigor. Gosto do ensinamento de que devemos agir da melhor maneira possível, sem nos apegarmos aos frutos do nosso esforço. A tarefa de produzir conhecimentos, dialogar, ensinar e aprender, orientar a formação de outros pesquisadores, já é altamente prazerosa e gratificante. É uma satisfação observar como o saber histórico pode contribuir para o autoconhecimento, a educação (no melhor sentido da palavra) e a emancipação das pessoas e da sociedade como um todo. O reconhecimento, se ele existe, deve ser uma consequência natural. Quanto à minha trajetória pessoal, considero muito sábia a frase do filósofo Ortega y Gasset de que "eu sou eu e as minhas circunstâncias". O esforço pessoal interage com o que a vida nos traz nos lugares e momentos específicos em que estamos vivenciando. Tive a oportunidade de ter uma formação acadêmica bastante sólida, podendo estudar com grandes professores. $\mathrm{O}$ encontro em 1982 com o professor Warren Dean, um dos pioneiros na criação da história ambiental, me permitiu conhecer esse campo de investigação de forma relativamente precoce. Mas também vivi momentos de grande aprendizado fora da academia, como nas lutas políticas e sociais que, a partir da década de 1970, trabalharam pela redemocratização do Brasil e pela busca de novos caminhos e utopias no plano individual e social. Se produzi alguma coisa de relevante como pesquisador, foi no somatório de todas essas experiências.

Fale um pouco sobre sua trajetória acadêmica principalmente sobre as motivações tanto para a escolha de um curso de graduação quanto para a escolha dos temas de pesquisa;

No final da década de 1970, quando entrei para a universidade, algumas questões estavam se apresentando com muita força para quem estava inquieto do ponto de vista pessoal, político e intelectual. Um compromisso muito forte era com a busca de novos caminhos para o Brasil. 
O contexto da ditadura nos forçava a repensar a trajetória do país, inclusive nos seus aspectos mais obscuros. Outro ponto crucial era o da crise da civilização industrial e a necessidade de repensar o dogma do crescimento ilimitado diante da um planeta finito, já que as fricções e desequilíbrios na interface entre as sociedades e o planeta explodiam por toda parte. Ou então a necessidade de repensar a vida pessoal e subjetiva no contexto das utopias socialistas, que muitas vezes nulificavam as necessidades e conflitos dos seres humanos realmente existentes em favor de esquemas rígidos baseados apenas nas classes sociais. Um outro aspecto importante era a revolução que estava ocorrendo nas ciências naturais, estimulando novas compreensões do que se entende por Natureza e por "ser humano". Diante dessas questões, eu procurei estudar um conjunto amplo de saberes, incluindo psicologia, ecologia, sociologia, economia e história. Além disso, desde jovem eu militava em movimentos em favor da redemocratização, da transformação social e do combate à degradação ambiental. Meus dilemas não eram apenas intelectuais. Quando entrei para a universidade, não foi fácil equacionar essa diversidade de interesses com a institucionalidade acadêmica. Até hoje não é fácil! Passei pela economia e pela sociologia. Mas a descoberta da história ambiental foi uma verdadeira revelação para mim, pois encontrei uma forma de pesquisa histórica que buscava o diálogo interdisciplinar, aproximando-se da geografia, da ecologia, da antropologia etc. Foi uma forma de juntar meus vários interesses. Hoje vejo que se trata de um saber sistêmico, no sentido em que falava Edgar Morin: não um saber que busca conhecer tudo, pois isso seria impossível. Mas sim que busca entender o mundo como interação dinâmica, que busca perceber como os diferentes aspectos da realidade estão sempre interconectados.

O que motivou a escrever o livro "Um sopro de destruição"?

Quando eu comecei a buscar alternativas de pesquisa em história ambiental, um campo bastante vasto se abriu. Um aspecto interessante foi o da dimensão ambiental das revoluções industriais e dos processos de industrialização. Existia por exemplo, a questão das fontes de energia, da importância dos combustíveis fósseis, das mudanças radicais na paisagem, da poluição do espaço vivido, dos novos padrões de produção e consumo, da ideologia do crescimento ilimitado etc. É interessante que estou voltando a esses temas hoje, na medida em estou estudando a história mais recente do Brasil, no contexto do Antropoceno e da chamada "Grande Aceleração" planetária depois da Segunda Guerra Mundial. Outro tema 
que me interessou desde o início foi o da dimensão ambiental dos "ciclos econômicos" que alguns historiadores identificaram na formação do Brasil. Quando se fala de pau-brasil, cana, mineração, café, é obvio que se abre um enorme espaço para pensar as interações entre as estruturas econômico-culturais e a diversidade biofísica do território. Hoje eu não utilizo a ideia de "ciclos", que me parece um tanto rígida e simplificadora. Eu prefiro pensar em uma diversidade de complexos histórico-ambientais que vieram se estabelecendo regionalmente e possuindo diferentes temporalidades nas suas trajetórias, desdobramentos e articulações. No andamento das minhas pesquisas, eu busquei documentos relativos às interações "bioculturais", para usar um conceito mais recente, nas diferentes regiões do país. Daí comecei a perceber a existência de um debate riquíssimo, desde o século XVIII, sobre o desflorestamento, a erosão dos solos, a perda de espécies, as mudanças climáticas e outros temas que hoje associamos ao campo "ambiental". A reconstituição histórica desse debate tanto na capital quanto em várias regiões - foi, como muitas vezes acontece na pesquisa histórica, semelhante ao de um "detetive". Como era um trabalho pioneiro, tive que reconstruir aquela rede de pensamento, um autor levando ao outro, um documento ou arquivo indicando outros e assim por diante. No final foi possível entender, com alguma coerência, a evolução daquele debate entre o final do século XVIII e o final do século XIX.

Dentre as figuras sobre as quais já pesquisou, quais as que mais chamaram a atenção e por que? Algum deles pode contribuir para pensar a atualidade do Brasil?

A descoberta daquele material foi uma grande surpresa. Eu considerava, como outros cientistas sociais, que a preocupação ambiental era um fenômeno da contemporaneidade. Uma lição nesse caso é que o historiador não deve se conformar com o senso comum. É interessante que mais ou menos na mesma época outros historiadores começaram a descobrir fontes semelhantes em várias regiões do planeta, percebendo que a preocupação ambiental não nasce, como imaginávamos, no mundo industrial avançado, mas já se manifestava, por exemplo, no contexto da forte exploração do mundo natural nas regiões coloniais e póscoloniais. Por outro lado, creio que quase tudo do que aparece naqueles documentos é relevante para pensar a atualidade ambiental do Brasil. A história, para mim, é sempre um jogo de continuidades e descontinuidades. É evidente que muitos dos problemas que estavam sendo discutidos nos séculos XVIII e XIX, como as queimadas e a erosão dos solos, são ainda 
uma triste realidade no país. Foi uma experiência extraordinária observar a sagacidade de vários dos observadores que estavam buscando criticar os problemas ambientais presentes em diferentes províncias do Brasil. Eles foram capazes de afirmar, muito antes do conceito de "biodiversidade", que o desflorestamento estava provocando a perda irreversível de espécies valiosas. Ou que o escravismo favorecia a degradação dos solos. Ou que as secas no Nordeste precisavam ser relacionadas com o desflorestamento. Tudo isso mostra também a riqueza pouco conhecida do pensamento brasileiro. Em certos momentos, personagens quase esquecidos na nossa memória social, demonstram uma sagacidade surpreendente até no contexto do debate contemporâneo. É o caso do jornalista Pedro Caldeira, em 1889, que afirmava que as chamadas "pragas" agrícolas não existem por si mesmas, mas são uma consequência dos desequilíbrios provocados pela ação humana

\section{Você se considera historiador militante?}

Não gosto muito dessa expressão. Acho importante separar as coisas. Me considero, de um lado, um cidadão que procura ser consciente da realidade do seu tempo e que está comprometido com certos valores, como democracia, justiça, respeito pela vida e cuidado ambiental. Do outro lado, além de cidadão ativo, sou um historiador profissional, comprometido com o rigor, a racionalidade e a demonstração documental de tudo que estou afirmando. Não é aceitável em nenhuma hipótese, por exemplo, falsificar ou deturpar o que a investigação está revelando em favor de um posicionamento político. Dito isso, é claro que muitos analistas já constataram a dificuldade de separar o indivíduo político do historiador. Manter o equilíbrio deve ser um esforço constante de ética e seriedade por parte de cada pesquisador. Mas é verdade também que essa conexão pode ser vista de forma mais positiva. Os documentos revelados no livro Um Sopro de Destruição nunca foram fisicamente perdidos. Sempre estiveram disponíveis nos arquivos e bibliotecas. Minha sensibilidade ambiental, no caso, também forjada no ativismo, me auxiliou a perceber o que outros historiadores haviam deixado de lado: a existência de uma tradição coerente do que chamei, em um esforço de qualificação retrospectiva, de "crítica ambiental" no Brasil dos séculos XVIII e XIX (que não deve ser confundida com "ambientalismo" no sentido contemporâneo). Não posso negar, além disso, que a descoberta daquela documentação me causou um certo prazer político, pois revelava que, ao contrário do que muitos diziam na época, a preocupação com a degradação do território não era um fenômeno "recente" ou "importado" na formação 
do Brasil. Mas tive o cuidado de não inventar nada com base nos meus desejos. Está tudo demonstrado e colocado no contexto intelectual do passado. Uma leitura não apressada do trabalho também demonstra que não procurei forçar um "ambientalismo" precursor. Até porque não acredito na ideia de "precursores", já que a evolução do pensamento social não é linear. Apenas demonstrei que a preocupação existia.

\section{Como foi seu primeiro contato com o Greenpeace?}

No final da década de 1980, eu trabalhava como professor de história na PUC-RJ e pesquisador no IBASE, uma organização dirigida pelo inesquecível Betinho. Também colaborava com alguns grupos ativistas. Eu participei, por exemplo, do apoio ao movimento dos seringueiros no Acre, tendo a oportunidade de me tornar amigo de outro personagem inesquecível: Chico Mendes. Como já havia publicado alguns livros e artigos sobre ecologia política, fui procurado pela Greenpeace, que estava querendo instalar-se na América Latina. Com a abertura do escritório do Brasil, em 1990, fui convidado para ser coordenador da área de florestas em toda a região. Acabei aceitando o desafio e vivendo uma experiência muito marcante, que durou até 1996. Aqui existe espaço para mencionar apenas um aspecto, no contexto da nossa conversa. Ao contrário do que um academicismo fechado pode imaginar, creio que aprendi muito como historiador e cientista social através das lutas da Greenpeace. Não se aprende apenas na academia. É verdade que o trabalho era muito absorvente e fui obrigado a abandonar as minhas tarefas formais de ensino e pesquisa. Mas, em compensação, convivi intensamente com situações de conflito e busca de alternativas sustentáveis em espaços florestais do México ao Chile, com foco na Amazônia. Além disso, pude trabalhar também em outros continentes além da América Latina, desenvolvendo uma visão planetária e comparativa dos problemas socioambientais. É claro que o objetivo central era conseguir resultados concretos e fico satisfeito com algumas vitórias que tivemos. Mas quem tem vocação de pesquisador nunca para de ler, estudar e aprender com a vida. Quando voltei para a universidade, creio que estava muito mais preparado do que antes para pensar as complexidades da história.

Na sua opinião, qual o papel dos movimentos sociais na atualidade? 
É um papel fundamental, que deveria ser aceito como relevante e benéfico por todos os setores da sociedade. O fato é que, na realidade complexa do mundo atual, os partidos e instituições políticas não são um canal suficiente para expressar a variedade de direitos que se deve defender e aperfeiçoar, de conflitos locais ou globais que precisam ser enfrentados e de projetos de transformação social que são almejados por diferentes grupos sociais. Os movimentos são uma maneira criativa e organizada - inclusive valendo-se de realidades novas, como a expansão e democratização dos meios de comunicação - de canalizar visões, propostas e práticas que podem fazer as sociedades avançarem de maneira inclusiva e participante, fortalecendo a cidadania. Acho importante, aliás, que os movimentos não apenas façam propostas para o futuro, mas também construam no aqui e no agora formas alternativas de educação, economia e vida social. É essencial, no entanto, que sejam autônomos e democráticos. E que também não desprezem o espaço específico dos partidos e da política formal. Mesmo com todas as suas imperfeições e injustiças, que precisam ser constantemente enfrentadas, o espaço da política formal é muito relevante. Creio que os movimentos sociais e os partidos podem e devem ser complementares na criação da sinergia social necessária para o avanço substantivo da democracia, da justiça e do cuidado ambiental.

Como a História Ambiental pode ajudar no debate sobre as rápidas transformações em nossa época, principalmente no Brasil?

Como disse acima, o conhecimento histórico é essencial para a educação popular e a emancipação social. Os problemas, injustiças e desequilíbrios que a sociedade hoje enfrenta não nasceram do nada, mas sim de dinâmicas anteriores que precisam ser analisadas em sua concretude e complexidade. Como dizia Paulo Freire, "o mundo não é, o mundo está sendo". A realidade é dinâmica e em permanente transformação. O conhecimento histórico é um instrumento poderoso para visualizar esse fluxo e pensar o passado no contexto das perguntas e desafios do presente e do futuro. O conhecimento histórico ambiental, por sua vez, deve ser visto como uma proposta de ampliação do conhecimento histórico. Os seres humanos não existem no vazio, não flutuam no espaço. As sociedades existem sempre em lugares específicos do planeta e precisam conviver com uma grande diversidade de seres não humanos e de realidades ecológicas (os movimentos das águas, a constituição dos solos, as 
oscilações do clima etc.). Está tudo interconectado de maneira muito dinâmica. Os movimentos da história humana interagem todo o tempo com os demais movimentos biofísicos do planeta. A proposta da História Ambiental, portanto, é construir uma leitura mais integrada e inclusiva da realidade social e ambiental, aperfeiçoando nosso entendimento do mundo. E as boas propostas sociais e políticas não podem prescindir do estudo, do debate, da reflexão coletiva e do direito de acesso ao melhor conhecimento que esteja sendo produzido pelos diferentes ramos do saber. 